\title{
Aboriginal Adolescents, Critical Media Health Literacy, and the Creation of a Graphic Novel Health Education Tool
}

\author{
Robin M. Wilmot, Deborah L. Begoray, and Elizabeth M. Banister \\ University of Victoria
}

\begin{abstract}
As Coyote tossed his eyes the next time, the ravens swooped, swift as arrows from a strong bow.

One of them snatched one eye and the other raven caught the other eye.

"Quoh! Quoh! Quoh'," they laughed, and flew away to the Sun-dance camp. (Quintasket, 1933)
\end{abstract}

The knowledge mobilization project involving Aboriginal students described in this article is an extension of a multi-phase, longitudinal, interdisciplinary research project aimed at understanding the processes through which adolescents develop critical media health literacy (CMHL) (Wharf Higgins \& Begoray, 2012; Wharf Higgins, Begoray, Beer, Harrison, \& Collins, 2012). The primary purpose of this project was to create a culturally relevant CMHL health education graphic novel. An additional purpose was to develop pedagogical approaches to be used to stimulate discussion around mediaperpetuated health messages with Aboriginal adolescents: Like Coyote, they too have had their eyes snatched. In brief, we collaborated with Aboriginal students to create culturally sensitive material representative of their identities as media-affected adolescents in the $21^{\text {st }}$ century. In turn, the dialogic process utilized during our project appeared to be a viable pedagogical approach when working with CMHL and Aboriginal adolescents, a supposition that will be the subject of our further research in the fall of 2013. Throughout the project, the authors, all of whom are non-Indigenous, were guided in their use of Indigenous ways of knowing by the Aboriginal education community.

Keywords: Aboriginal adolescent health; health education; critical media health literacy; graphic novels as health education tools

Author Note: The authors gratefully acknowledges the financial support of the Canadian Institues of Health Research (CIHR \#293119) in the funding of this project. 


\title{
Aboriginal Adolescents, Critical Media Health Literacy, and the
}

\section{Creation of a Graphic Novel}

\author{
As Coyote tossed his eyes the next time, the ravens swooped, \\ swift as arrows from a strong bow. \\ One of them snatched one eye and the other raven caught the other eye. \\ "Quoh! Quoh! Quoh'," they laughed, \\ and flew away to the Sun-dance camp. (Quintasket, 1933)
}

\section{Health Education Tool}

Popular media, a dominant force in the lives of adolescents (Alvermann \& Hagood, 2000), provide key channels through which health information is either explicitly or implicitly conveyed to this age group (Begoray, Cimon, \& Wharf Higgins, 2010). Critical media health literacy (CMHL) equips adolescents to think critically about these messages in order to promote health literacy (Flecha, Garcia, \& Rudd, 2011), health enhancing behaviours (Brey, Clark, \& Wantz, 2008) and skills (Kickbusch, 2008) essential for wellbeing. We define CMHL as: "a right of citizenship [that] empowers individuals and groups, in a risky consumer society, to critically interpret and use media as a means to engage in decision-making processes and dialogues; exert control over their health and everyday events; and make healthy changes for themselves and their communities" (Wharf Higgins \& Begoray, 2012, p. 142).

The impact of media-perpetuated messages on the developing health-related attitudes, habits, and behaviours of adolescents are substantive, and tend to be sustained into adulthood (Marx, Hudson, Deal, Pateman, \& Middleton, 2007). Researchers have documented that media can have positive or detrimental influences on body image (Smolak \& Stein, 2006; Tiggemann \& Miller, 2010), eating habits (Utter, NeumarkSztainer, Wall, \& Story, 2003), and self-esteem (Frisén \& Holmqvist, 2010). But while public service announcements and health educators use the media to promote healthy behaviours, advertisers use their considerable financial advantage to target youth consumers to increase consumption. In so doing, they normalize behaviours that are potentially unhealthy (Brey, Clark, \& Wantz, 2008) such as smoking (Pollay, 2000), abuses of alcohol (Ford, Weintraub, Austin, \& Hust, 2006), and of food (Palmer \& Carpenter, 2006; Weber, Story, \& Harnack, 2006).

Critical evaluation of health information transmitted via the media is even more crucial for Aboriginal adolescents who are at far more risk of poor health than the general population (Canadian Federation for Sexual Health, 2007). There are more than 600 First Nations in Canada and each one has its unique customs, language, social structure, and history (Ball, 2004); however, some generalizations can be made. Cultural discontinuity, oppression, and marginalization have been linked to high rates of depression, alcoholism, suicide, and violence in many Indigenous communities, with the greatest impact on adolescents (Kirmayer, Brass, \& Tait, 2000). Colonialism and the Indian residential school program have also torn at the fabric of Indigenous life and have harmed the identity of Aboriginal peoples by disrupting "the cultural continuity that led to the passing on of knowledge and skills from one generation to the next” (Hare, 2005, p. 251). 
Nevertheless, widespread traditions and beliefs link Indigenous peoples together (Banister \& Begoray, 2013). This loss of cultural identity is of critical concern for Canadian Aboriginal people, particularly those in rural and remote areas (Richmond \& Ross, 2009), and has a major impact on health decisions. For many Aboriginal people, the connection with the "traditional lands and the cultural, spiritual and economic roots it nurtured for health” (Richmond \& Ross, 2009, p.410) has been severed. This loss of identity has created confusion and poor health choices for many Aboriginal youth (Richmond \& Ross, 2009).

\section{Philosophical/Theoretical Frameworks}

As a group of middle-aged, Caucasian, women we have had numerous experiences working with Aboriginal adolescents. For example, in one research project Deborah and Elizabeth undertook gender-sensitive and culturally appropriate sexual health literacy education for young Aboriginal women through the study of their dating relationships. The ten participants were adolescents attending a rural, community-based school that was operated by the local band school board. In this research, three main strategies were adopted: a group format congruent with Aboriginal ways of knowing, particularly what Couture (1991) calls, "mind-in-relational activity"; speaking and listening in a circle, a deeply rooted Aboriginal practice of power sharing which conveys mutual respect and flattens power relations; and discussion to foster critical thinking, for example, discussing stereotypical gender roles and the predominance of White faces in media advertising (Banister \& Begoray, 2006).

We undertook the creation of a graphic novel that focused on CMHL as sociocultural educators. Sociocultural approaches in educational practice point to the importance of "culturally responsive pedagogy with multicultural curricula that draws on the funds of knowledge of our communities" (Gainer, 2012, p. 14). Sociocultural theory suggests that learning is most effective when the knowledge dissemination tools used, in this case those that facilitate the development of CMHL for Aboriginal students, are situated in familiar, relevant contexts that reflect the lived experiences of the learners (Nguyen, 2011).

Researchers assert that Aboriginal students' ability to learn is strongly tied to how harmoniously their cultural identities match that which they are to learn or the pedagogical practices used in the learning environment (e.g. Pirbhai-Illich, 2010). Like Coyote in the quote above, Aboriginal students have had their "eyes" on the world "snatched" and devalued by the messaging of the dominant culture. Frequently, epistemological and pedagogical mismatches exist between Indigenous ways of knowing and the approaches used in traditional Western schools (Banister \& Begoray, 2013). Aboriginal students often find themselves in environments where their Indigenous knowledge is viewed as deficient (Brayboy \& Maughan, 2009). Nguyen (2011) stresses the importance of having congruency between the worldviews of Aboriginal students and those underpinning the educational programs in their schools. This approach begins with an understanding of their culture. When Indigenous knowledge is emphasized, Indigenous adolescents experience their cultural knowledge and traditions and have the opportunity for "finding themselves" (Hare, 2005, p. 261) and establishing an Aboriginal identity. 
Aboriginal knowledge is "personal, oral, experiential, holistic, and conveyed in narrative or metaphorical language" (Castellano, 2000, p. 25). Epistemologically, for Aboriginal people knowledge exists in the spiritual, emotional, cognitive, and physical realms, each equal in importance as "mentors" and sources of wisdom (Greenwood, 2005). Thus, for the Aboriginal student, an optimal learning environment includes people (self, family, Elders, and community); the land (traditional skills); Indigenous languages, traditions, and cultures; and spirituality (Canadian Council on Learning, 2009). We strove to utilize Aboriginal ways of knowing to strengthen and make relevant the work we did with the youth around CMHL. Partnership with the Aboriginal education community allowed for the local cultural stories, traditions and histories to be respected, celebrated, and intertwined with CMHL concepts; a partnership that supported our participants through discussion and story which explored the relevance of these concepts to their lives as Aboriginal adolescents.

We also took the stance that the creation of the graphic novel would involve social constructivism. The creation of the novel would be a reciprocal process: The youth writers would be involved in a process of exploring their own understanding of what it means to be $\mathrm{CMH}$ literate, and this process, as represented in the novel, would have the power to reach out to others in similar life situations and ages. Our teaching approach emphasized, "learning by observation and doing, learning through authentic experiences ....and learning through enjoyment” (Battiste, 2002, p. 18), important qualities in a teaching situation for all adolescents and especially important for Aboriginal adolescent learners.

Finally, we endeavoured to create a dialogic situation in the writing workshop that invited questioning, multiple perspectives, and lively debate (Ciardiello, 2007; Juzwik, Nystrand, Kelly, \& Sherry, 2008), as the participants strove to understand the issues involved in becoming critical media health literate in terms of their own backgrounds, belief systems, experiences and those of others. We attempted to "flatten the power hierarchies" (Fecho \& Botsakis, 2007, p.150) to allow the students to explore, through their own eyes, how media-perpetuated health issues were relevant for them as Aboriginal adolescents.

\section{The Graphic Novel Format}

The graphic novel offered visual characteristics consistent with media messages. Graphic novels are now a popular genre for adolescents. While some prejudice still exists against them as being easy or frivolous reading, most educators now realize that graphic novels can in fact be complex, high quality literature (e.g. Pantaleo, 2011). For example, Schwarz (2011) comments that "many graphic novels lend themselves well to teaching media/multiple literacies, supporting adolescent development, and helping students grapple with diversity issues" (Schwarz \& Crenshaw, p. 52). We began by choosing the graphic novel as a format that would be appealing to adolescent writers, and which would be appealing to a prospective audience of adolescent readers.

We noted as well that there was precedence for the use of graphic novels to introduce health-related issues to Aboriginal students. The Health Aboriginal Network also uses a comic book/graphic novel format to promote health by integrating Aboriginal 
culture into health-based narratives. Their offerings such as Kiss Me Deadly (Van Camp, 2011), which addresses sexual health and Just a Story (Sanderson, 2009), which addresses mental health use ideas from Aboriginal adolescents, which are then illustrated by professional artists, a strategy that we also utilized.

\section{Methodology}

To create a tool capable of mobilizing CMHL findings to an Aboriginal adolescent audience in culturally sensitive ways, we commissioned six middle/high school Canadian Aboriginal students, ages 12 to 15, to create the storyline for a graphic novel that illustrated the effects of media on the developing health habits and attitudes of Aboriginal adolescents. The graphic novel was planned to explain in narrative format with accompanying visuals how popular media attract the attention of adolescents, and the resultant effects that they have on health and health habits. This unique knowledge mobilization strategy capitalized on both expert knowledge (from Aboriginal and nonAboriginal adults) and Aboriginal adolescent peer-to-peer communication. In so doing, it leveraged the credibility and relevance of the message. A highly regarded local Aboriginal artist added the illustrations, based on the storyline developed by the students. Adopting a dialogic approach to this particular project allowed us to incorporate key Aboriginal ways of knowing and learning: oracy, storytelling, community, and contribution. At the same time, the dialogic approach empowered the adolescents to guide us and the intended novel audience in an exploration of the issues pertinent to health as portrayed through the media.

\section{Perspective}

We invited our six student authors to give voice to their perspectives and experiences with media-perpetuated health messages and suggested that they consider engaging an audience of younger adolescents, 11 and 12 years old. Previous research has taught us that, though adolescents rarely believe they are taken in by media messages, they frequently believe that a young audience may be duped (Begoray, Wharf Higgins, Harrison, \& Collins-Emery, 2013).

\section{The Setting}

This project was set in a semi-rural community in Western Canada. One month prior to the project's launch, we met with the assistant superintendent, the district Aboriginal principal, and a district teacher to explain our workshop plan. With their support, we met with the chosen potential students and teacher participants, as well as with other members of the local Aboriginal education community to explain the project. The enthusiastic tone of these initial meetings reflected the importance attributed to and the potential contribution by students to enhancing the ability of adolescents to make positive decisions around their health.

We conducted our project as a workshop that took place over five consecutive half days. Each day, in addition to the six student writers, an Aboriginal teacher and Aboriginal artist participated in the activities. Most days, additional members of the Aboriginal educational community joined us of their own volition, consistent with their value of community, for at least a portion of the morning. 
We gathered in a room that was initially devoid of wall decorations. As teachers who are dedicated to a dialogical approach to teaching and learning, we were intentional about creating "space" for our students to act as guides, and this was represented by the physical "space" reserved for them. During the workshop, the walls gradually filled with the writers' understandings of CMHL and with the emerging storyline.

\section{Community and Aboriginal Worldviews}

Throughout this project, there was a sense of community that enveloped our group, a community that provided an Aboriginal cultural context. From the introductory meeting to the conclusion of the last day of the workshop, the Aboriginal students were surrounded by an engaged adult support group. Empowering the students to create a story that would act as an important teaching tool to be used by other adolescents required responsibility on the part of both the students and the adults. We could not have imagined how naturally this could occur until we observed it happening. The adults, in response to discussion topics, provided key stories and demonstrations of culture that explained Aboriginal values and practices. The students in turn sifted through these inputs, choosing what was relevant to them and what they believed would be relevant to an audience of other younger Aboriginal students.

Perhaps the following examples will allow readers to understand the richness of the environment. An Elder opened our time together by blessing the project through song and drumming, while the First Nations Principal offered a prayer in her language and a traditional acknowledgement of the people whose traditional territory we were working in. The Aboriginal teacher and the artist, on a daily basis, shared the stories of the traditional territories, creating a bridge between the values of the Aboriginal community and the CMHL concepts being discussed. Finally, an Aboriginal language specialist from the local band delivered a lesson that ignited discussion around the ways in which language reveals culture, resulting in Aboriginal names for the main characters of the story. Language both preserves and categorizes knowledge in culturally significant manners (McKeough et al., 2008). This exchange added yet another layer to our students' understanding of CMHL in terms of their own culture. Coyote, as the deceptive, sneaky trickster, who could, however, also be tricked, came alive as we attempted to approximate the regional pronunciation of K'ist (bad) to describe coyote and Yo-yot (strength) to indicate the students' main character's ability to resist the homogenizing forces of the media.

Throughout the workshop, our door was open to anyone who cared to visit, and on most days, various members of the Aboriginal community joined us. Community involvement in the education of Aboriginal students is important to the Indigenous people (McKeough et al., 2008) and certainly, that was demonstrated during our time with these students. Adolescents need a broad circle of influence (CCL, 2009; White-Kaulaity, 2007); therefore, involving community members increases the effectiveness of educational programs. Greenwood (2005) reminds us that the Canadian constitution clearly affirms that Aboriginal students have the right to understand, learn, and participate in all aspects of their culture. Collaboration of Indigenous teachers and community members integrates Indigenous knowledge into learning. In return, Indigenous youth are expected to contribute to the welfare of the community (Battiste, 
2002; Waller, Okamoto, Hankerson, \& Hibbeler, 2002). We heard stories spontaneously told that added to our understanding of the ways in which culture is transmitted and the ways in which culture infuses the decision-making processes of this Aboriginal group of people. We shared research, strategies, and examples of CMHL, while the Aboriginal adults provided traditional stories that linked our contributions with their cultural beliefs. In exchange for surrendering control over the project, we left our five days together feeling enriched and privileged to have been a part of the cultural exchanges that occurred between the adults and students.

\section{Activities and Insights}

Two key pedagogical insights emerged that were beneficial to the writers as they examined CMHL, and may assist readers hoping to use a similar process in their classrooms.

First, critical literacy is "a dynamic process that examines power relationships, expands our thinking, and enlightens our perceptions...” (McLaughlin \& De Voogd, 2011, p. 281). However, middle and senior high school students do not necessarily explore multiple perspectives unless they are given the opportunity to do so (Applebee, Langer, Nystrand, \& Gamoran, 2003; Langer, 2001; Pierce \& Gilles, 2008; Santo, 2006). Researchers have found that when teachers guide their students to interact with issues multiple times, over successive days, student discussions become deeper and contain a larger number of exploratory ideas (Applebee, Langer, Nystrand, \& Gamoran, 2003; Langer, 2001). Each day we re-examined five key CMHL concepts, critical literacy questions, and the developing story in ways that asked students to bring different lenses to the issues. For example, students were asked to examine CMHL in terms of their cultural belief systems, of personal and collective value systems, of its mentoring of younger students, and of how language conveys culture.

Secondly, we provided a structure for our time together by introducing five media literacy education concepts taken from the work of Wharf-Higgins \& Begoray (2012) and seven key questions that the critically literate person asks about media messages (taken from NAMLE, 2007 as in Rogow, 2011, p.18). The concepts, listed below, were to be represented in the graphic novel, either through the written text and/or in the visuals, while the questions were to guide the students' development of CMHL as they engaged in discussions around media and health.

The five key concepts are:

1. Advertisements are ubiquitous and intent on controlling the purchasing habits of consumers. CMHL provides students with the tools to develop critical habits of thinking needed for adolescents to deconstruct the multiple messages competing for their attention (Wharf Higgins \& Begoray, 2012). Students ask, "How has this ad been constructed to appeal to me?"

2. Advertisements often create false reflections of reality. CMHL emphasizes that texts are ideologically based. Students are encouraged to ask themselves, "Do these really represent the racial, cultural, and physical population diversity? 
Are the body images realistic? What about gender stereotyping? How do these representations affect mental and physical health?”

3. Advertisements attract adolescents using hooks. For example, use of celebrity endorsements and promises of popularity or success create loyalty to products. Students learn to ask, "What is this ad promising in order to attract my attention?"

4. Advertisers aggressively target adolescents. Advertisers research adolescent identities, to create and use them to entice adolescents to adopt certain consumer habits. Students are encouraged to ask themselves questions such as, "Is the lifestyle associated with this product healthy? What are the advertisers not telling me about this product?"

5. CMHL allows adolescents to recognize, critique, and accept or reject mediaperpetuated identities and values. Students ask, "Do I want to be the person the ad is presenting?"

$\mathrm{CMH}$ literate adolescents are able to think critically about media-delivered health messages (Wharf Higgins \& Begoray, 2012). They have inquiring habits of mind equipped with a "broad range of critical and analytical skills to help them make their own choices and decisions about the ideological and political messages surrounding them in 21st century culture” (Chris Worsnop, personal communication, May 31, 2004, as cited in Rogow, 2004, p.3). We provided our participants with the following questions (NAMLE, 2007, as cited in Rogow, 2011, p.18) to guide them as they examined health messages in the media.

1. What is the purpose of the media message and who produced it?

2. Who is the intended audience for this message? How do you know?

3. "Who might benefit from this message? Who might be harmed?” (NAMLE, 2007, as cited in Rogow, 2011, p.18)

4. What strategies are used in the media message to grab your attention?

5. What information is given; what is left out, and why?

6. What values are evident in the messages? How do they represent your values?

7. Is the information given in this message trustworthy? How do you know?

\section{Conclusion and Future Directions}

Improving health literacy is a way to reduce health inequities (Ghaddar, Valerio, \& Hansen, 2012), and address social exclusion (European Commission, 2010). Adolescents who are health literate critically question these media-perpetuated messages, allowing them consciously to take charge of their health decisions (Begoray et al., 2013).

The completed health education tool is 20 pages in length, professionally illustrated, and in the process of being published. It is our intention to use this tool in health education classes to promote the development of CMHL, especially with 
Aboriginal adolescent students. Each group that we work with on CMHL finds different aspects of media-perpetuated health messages relevant, and this group, too, discovered their own truths. This group focused on the deceptiveness of Photoshopping models and the ways in which advertisers homogenize what it means to be fashionable and attractive, practices that they reasoned resulted in low self-esteem issues for many youth. They told a story about the ways in which advertisers dictate a largely unachievable norm about what it means to be fashionable and attractive. Coyote, the mythical character who teaches youth through his connivance, emerges as the voice of corporate advertising and of media pressure to conform. The characters did outwit the trickster, whose vested interest in shaping the identities of youth for financial gain was clear throughout the novel.

Critical media literacy demands facility with multiple semiotic systems that work in tandem with one another, including those that govern written, aural, and visual representations (New London Group, 1996). The graphic novel provided us with the opportunity to engage students in both visual and linguistic semiotic systems that are familiar to them. Kress (2003, as cited in Albers, Vasquez, \& Harste, 2011) says, "'the world told' is vastly different from 'the world shown'” (p.195). Both systems used in tandem produce more understanding and long term retention than using merely one or the other according to dual coding theory (Sadoski \& Paivio, 2001).

Further, while we trusted that our Aboriginal students would create a story that was recognizable to other Aboriginal students, we also realized potential readers would overlay the story with their personal experiences (Rosenblatt, 1994). CMHL develops through opportunities for individuals to examine critically materials that represent the ambiguous nature of real life; therefore, the presentation of the health media messages in this graphic novel were meant to be subtle, leaving the possibility open for readers to respond to the story text and graphics critically and in personally relevant ways. In sum, the rich visuals and the story line provided the ideal vehicle for delivering CMHL concepts, creating a tool that could act as a catalyst to discussion.

In addition to the creation of a tool capable of mobilizing findings about CMHL to adolescents, we also noted that the process used to create the novel appeared to be a promising pedagogical approach that may be useful to teachers hoping to engage Aboriginal students in discussions around media-perpetuated health messages. The pedagogical value of positioning Aboriginal students as mentors to younger students in a dialogic, collaborative teaching environment that is culturally supported by the educational Aboriginal community is worthy of further investigation. 


\section{References}

Albers, P., Vasquez, V., \& Harste, J.C. (2011). Making Visual Analysis Critical. In D. Lapp \& D. Fisher (Eds). Handbook of Research on Teaching the English Language Arts Third Edition (pp. 195-201). New York, NY: Routledge Taylor \& Francis Group.

Alvermann, D., \& Hagood, M. (2000). Critical media literacy: Research, theory, and practice in "New Times”. The Journal of Educational Research, 93(3), 193-205.

Applebee, A. N., Langer, J. A., Nystrand, M., \& Gamoran, A. (2003). Discussionbasedapproaches to developing understanding: Classroom instruction and student performance in middle and high school English. American Educational Research Journal, 40(3), 685-730.

Ball, J. (2004). As if indigenous knowledge and communities mattered: Transformative education in First Nations communities in Canada. The American Indian Quarterly, 28(3), 454-479.

Banister, E. M., \& Begoray, D. L. (2006). Adolescent girls' sexual health education in an Indigenous context. Canadian Journal of Native Education. 29(1), 75-86.

Banister, E., \& Begoray, D. (2013). Using Indigenous research practices to transform Indigenous literacy education: A Canadian study. Journal of American Indian Education, 52(1), 65-80.

Battiste, M. (2002). Indigenous knowledge and pedagogy in First Nations education: A literature review with recommendations. Ottawa, ON: Apamuwek Institute Ottawa.

Begoray, D., Cimon, M., Wharf Higgins, J. (2010). Mediating health: The powerful and role of the media. New York, NY: Nova Science Publishers, Inc.

Begoray, D., Wharf Higgins, J. W., Harrison, J., \& Collins-Emery, A. (2013). Adolescent reading/viewing of advertisements. Journal of Adolescent \& Adult Literacy, 57(2), 121-130.

Brayboy, B. M. J., \& Maughan, E. (2009). Indigenous knowledges and the story of the bean. Harvard Educational Review, 79(1), 1-21.

Brey, R. A., Clark, S. E., \& Wantz, M. S. (2008). This is your future: A case study approach to foster health literacy. Journal of School Health, 78(6), 351-355.

Canadian Council on Learning (2009). The state of Aboriginal learning in Canada:

A holistic approach to measuring success. Ottawa, ON: CCL. Retrieved from http://www.ccl-cca.ca/pdfs/StateAboriginalLearning/SAL-FINALReport_EN.PDF

Canadian Federation for Sexual Health (2007). Sexual health in Canada: Baseline 2007. Retrieve from http://www.cfsh.ca/Resources/Research/SexualHealthBaseline2007.aspx 
Castellano, M. B. (2000). Updating Aboriginal traditions of knowledge. In G.J. Sefa Dei, B.L. Hall, \& D. Goldin Rosenberg (Eds.), Indigenous knowledges in global contexts: Multiple readings of our World, (pp. 21-36).

Ciardiello, A. V. (2007). Puzzle them first! Newark: International Reading Association.

Couture, J. E. (1991). Explorations in native knowing. In J. W. Friesen (Ed.), The cultural maze: Complex questions on Native destiny in Western Canada* (pp. 53-73). Calgary, AB: Detselig Enterprises.

European Commission (2009). European survey on youth: Supporting young people to participate fully in society. Retrieved from http://ec.europa.eu/research/socialsciences/pdf/policy-review-youth_en.pdf

Fecho, B., \& Botzakis, S. (2007). Feasts of becoming: Imagining a literacy classroom based on dialogic beliefs. Journal of Adolescent and Adult Literacy, 50(7), 548558.

Flecha, A., García, R., \& Rudd, R. (2011). Using health literacy in school to overcome inequalities. European Journal of Education, 46(2), 209-218.

Ford, J.B., Weintraub, E., Austin, S., \& Hust, J.T. (2006). Alcohol advertising and youth. International Journal of Advertising, 25(4), Comments.

Frisén, A., \& Holmqvist, K. (2010). Physical, sociocultural, and behavioral factors associated with body-esteem in 16-year-old Swedish boys and girls. Sex Roles, 63(5), 373-385. doi: 10.1007/s11199-010-9806-2

Gainer, J. (2012). Critical thinking: Foundational for digital literacies and democracy. Journal of Adolescent and Adult Literacy, 56(1), 14-17.

Ghaddar, S. F., Valerio, M. A., Garcia, C. M., \& Hansen, L. (2012). Adolescent health literacy: The importance of credible sources for online health information. Journal of School Health, 82(1), 28-36.

Greenwood, M. (2005). Children as citizens of First Nations: Linking Indigenous health to early childhood development. Paediatrics \& Child Health, 10(9), 553.

Hare, J. (2005). To "know papers": Aboriginal perspectives on literacy. In J. Anderson, M. Kendrick, T. Rogers, \& S. Smythe (Eds.). Portraits of literacy across families, communities and schools: Tensions and intersections, (pp. 243-263).

Juzwik, M. M., Nystrand, M., Kelly, S., \& Sherry, M. B. (2008). Oral narrative genres as dialogic resources for classroom literature study: A contextualized case study of conversational narrative discussion. American Education Research Journal, 45(4), 1111-1154. doi: 10.3102/0002831208321444

Kickbusch, I. (2008). Policy innovation for health. New York: Springer.

Kirmayer, L. J., Brass, G. M., \& Tait, C. L. (2000). The mental health of Aboriginal peoples: Transformations of identity and community. The Canadian Journal of 
Psychiatry/La Revue Canadienne De Psychiatrie, 45(7), 607-616. Retrieved from https://ww1.cpa-apc.org/Publications/Archives/CJP/2000/Sep/Sep2000.asp

Langer, J. (2001). Beating the odds: Teaching middle and high school students to read and write well. American Educational Research Journal, 38(4), 837-880. doi: 10.3102/00028312038004837

Marx, E., Hudson, N., Deal, T. B., Pateman, B., \& Middleton, K. (2007). Promoting health literacy through the health education assessment project. Journal of School Health, 77(4), 157-163. doi: 10.1111/j.1746-1561.2007.00186.x

McKeough, A., Bird, S., Tourigny, E., Romaine, A., Graham, S., Ottmann, J., \& Jeary, J. (2008). Storytelling as a foundation to literacy development for Aboriginal children: Culturally and developmentally appropriate practices. Canadian Psychology/Psychologie Canadienne, 49(2), 148-154. doi: 10.1037/07085591.49.2.148

McLaughlin, M., \& De Voogd, G. (2011). Critical literacy as comprehension: Understanding at deeper levels. In D. Lapp \& D. Fisher (Eds.), Handbook of research on teaching the English language arts (3rd ed., pp. 278-282). New York, NY: Routledge Taylor \& Francis Group.

New London Group (1996). A pedagogy of multiliteracies: Designing social futures. Harvard Educational Review, 66(1), 60-92.

Nguyen, M. (2011). Closing the education gap: A case for aboriginal early childhood education in Canada, a look at the Aboriginal Headstart program. Canadian Journal of Education, 34(3), 229-248.

Pantaleo, S. (2011). Grade 7 students reading graphic novels: 'You need to do a lot of thinking. English in Education, 45(2), 113-131. doi: 10.1111/j.17548845.2011.01093.x

Palmer, E., \& Carpenter, C. (2006). Food and beverage marketing to children and youth: Trends and issues. Media Psychology, 8(2), 165-190.

Pierce, K., \& Gilles, C. (2008.). From exploratory talk to critical conversations. In N. Mercer \& S. Hodgkinson (Eds.), Exploring talk in school: Inspired by the work of Douglas Barnes (pp. 37-53).

Pirbhai-Illich, F. (2010). Aboriginal students engaging and struggling with critical multiliteracies. Journal of Adolescent \& Adult Literacy, 54(4), 257-266.

Pollay, R.W. (2000). Targeting youth and concerned smokers: Evidence from Canadian tobacco industry documents. Tobacco Control, 9(2), 136-147. doi: 10.1136/tc.9.2.136

Quintasket, C. (1933). Okanoga -Coyote juggles his eyes. Retrieved from http://www.ucan-online.org/legend.asp?legend=6091\&category=8 
Richmond, C. A., \& Ross, N. A. (2009). The determinants of First Nation and Inuit health: A critical population health approach. Health \& Place, 15(2), 403-411.

Rogow, F. (2004). Shifting from media to literacy: One opinion on the challenges of media literacy education. American Behavioral Scientist, 48(1), 30-34. doi:10.1177/0002764204267248

Rogow, F. (2011). Ask, don't tell: Pedagogy for media literacy education in the next decade. Journal of Media Literacy Education, 3(1) 16-22. Retrieved from http://digitalcommons.uri.edu/jmle/vol3/iss1/8

Rosenblatt, L. M. (1994). The reader, the text, the poem: The transactional theory of the literary work. Carbondale, IL: Southern Illinois University Press.

Sadoski, M., \& Paivio, A. (2001). Imagery and text: A dual coding theory of reading and writing. Mahwah, New Jersey: Lawrence Erlbaum Associates.

Sanderson, S. (2009). Just a story. Retrieved from http://www.thehealthyAboriginal.net/ Canada: The Healthy Aboriginal Network.

Santo, C. (2006). A vision of adolescent literacy: Ours or theirs? Journal of Adolescent and Adult Literacy, 49(6.2), 466-476.

Schwarz, G., \& Crenshaw, C. (2011). Old media, new media: The graphic novel as bildungsroman. Journal of Media Literacy Education, 3(1), 4.

Smolak, L., \& Stein, J. A. (2006). The relationship of drive for muscularity to sociocultural factors, self- esteem, physical attributes gender role, and social comparison in middle school boys. Body Image, 3(2), 121-129. doi: 10.1016/j.bodyim.2006.03.002

Tiggemann, M., \& Miller, J. (2010). The internet and adolescent girls' weight satisfaction and drive for thinness. Sex Roles, 63(1-2), 79-90. doi: 10.1007/s11199-010-9789-z

Utter, J., Neumark-Sztainer, J., Wall, M., \& Story, M. (2003). Reading magazine articles about dieting and associated weight control behaviours among adolescents. Journal of Adolescent Health, 32(1), 78-82.

Van Camp, R. (2011). Kiss me deadly. Retrieve from http://www.thehealthyAboriginal.net/. Canada: Healthy Aboriginal Network.

Waller, M. A., Okamoto, S. K., Hankerson, A. A., \& Hibbeler, T. (2002). The hoop of learning: A holistic, multisystemic model for facilitating educational resilience among Indigenous students. Journal of Sociology \& Social Welfare, 29(1), 97-116.

Weber, K., Story, M., \& Harnack, L. (2006). Internet food marketing strategies aimed at children and adolescents: A content analysis of food and beverage brand web sites. Journal of the American Dietetic Association, 106(9), 1463-1466.

White-Kaulaity, M. (2007). Reflections on Native American reading: A seed, a tool, and a weapon. Journal of Adolescent \& Adult Literacy, 50(7), 560-569. 
Wharf Higgins, J., \& Begoray, D. (2012). Exploring the borderlands between media and health: Conceptualizing 'critical media health literacy'. The Journal of Media Literacy Education, 4(2), 136-148. Retrieved from http://digitalcommons.uri.edu/cgi/viewcontent.cgi?article=1092\&context=jmle

Wharf Higgins, J., Begoray, D., Beer, C., Harrison, J., \& Collins, A. (2012). Strategies for measuring and maximizing health literacy of youth. In R. Marks (Ed), Health literacy and school-based health education (pp. 79-143). Lewes, UK: Emerald Publishing. 